\title{
PELATIHAN HOMEMADE PEPAYA SOAP BAGI KELOMPOK IBU PRODUKTIF DI KENAGARIAN SALIBUTAN KECAMATAN LUBUK ALUNG KABUPATEN PADANG PARIAMAN
}

\author{
Des $\mathbf{M}^{1}$, Mades Fifendy ${ }^{1}$, Elsa Yuniarti ${ }^{{ }^{*}}$, Rezi Junialdi ${ }^{\mathbf{2}}$ \\ ${ }^{1}$ Universitas Negeri Padang, ${ }^{2}$ Universitas Nahdlatul Ulama Sumatera Barat \\ *elsayuniarti@gmail.com
}

\begin{abstract}
Housewives in Nagari Salibutan are identical with taking care of the family at home, even though housewives can do productive activities to help family income by utilizing plantation products. Nagari Salibutan has an agricultural typology. In addition to rice fields and forests, Nagari has a fairly large plantation of 500 hectares. One of the garden products produced by Nagari Salibutan is Papaya Fruit. One of the products produced from papaya fruit is soap. Soap produced by papaya fruit is healthy because the manufacturing process is natural, this soap can also be used as an original souvenir of Kenagarian Salibutan. Besides that, soap from papaya fruit during the current COVID-19 pandemic, can be used by the public to wash their hands. From the analysis of the situation, people in Kenagarian Salibutan need to be equipped with knowledge of the use of Papaya Fruits into products of economic value such as soap, so that people do not only sell papayas at low prices.
\end{abstract}

Keywords: papaya; soap; productive mom.

\begin{abstract}
Abstrak
Ibu Rumah Tangga Nagari Salibutan identik dengan kegiatan mengurus keluarga dirumah, padahal Ibu Rumah Tangga bisa melakukan kegiatan produktif untuk membantu pendapatan keluarga dengan memanfaatkan hasil perkebunan. Nagari Salibutan memiliki tipologi pertanian. Selain sawah dan hutan Nagari ini memiliki perkebunan yang cukup luas yaitu $500 \mathrm{Ha}$. Salah satu hasil kebun yang dihasilkan Nagari Salibutan yaitu Buah Pepaya. Salah satu produk yang dihasilkan dari buah papaya yaitu Sabun. Sabun yang dihasilkan buah papaya sehat karena proses pembuatannya alami, sabun ini juga bisa dijadikan souvenir asli Kenagarian Salibutan. Disamping itu sabun dari buah papaya saat pandemi COVID-19 saat sekarang, bisa dimanfaatkan masyarakat untuk mencuci tangan. Dari analisis situasi, masyarakat di Kenagarian Salibutan perlu dibekali pengetahuan pemanfaatan Buah Pepaya menjadi produk bernilai ekonomi seperti sabun, sehingga masyarakat tidak hanya menjual buah papaya dengan harga yang murah.
\end{abstract}

Kata Kunci: pepaya; sabun; ibu produktif

Submitted: 2021-09-05

Revised: 2021-10-08

Accepted: 2021-10-31

\section{Pendahuluan}

Nagari Salibutan merupakan nagari yang berada didalam Kecamatan Lubuk Alung Kabupaten Padang Pariaman. Secara geografis nagari ini berbatasan sebelah Utara dengan Nagari Pasie Laweh, sebelah Selatan dengan Nagari Lubuk Alung (Kementerian Dalam Negeri Republik Indonesia Direktorat Jenderal Bina Pemerintahan Desa, 2020a).

Jumlah Kepala Keluarga di Kenagarian Salibutan sebanyak 512 KK, yangterdiri dari 374 KK keluarga sejahtera dan 138 KK keluarga prasejahtera. Dari jumlah KK tersebut masyarakat usia 1856 tahun yang menjadi Ibu Rumah Tangga sebanyak 42 orang (Kementerian Dalam Negeri Republik Indonesia Direktorat Jenderal Bina Pemerintahan Desa, 2020b). Selama ini Ibu Rumah Tangga identik dengan kegiatan mengurus keluarga di rumah, padahal Ibu Rumah Tangga bias melakukan kegiatan produktif lain untuk membantu pendapatan keluarga. Salah satu kegiatan produktif yang dapat dilakukan Ibu Rumah Tangga yaitu membuat sabun pepaya.

Nagari Salibutan memiliki tipologi pertanian. Selain sawah dan hutan Nagari ini memiliki perkebunan yang cukup luas yaitu 500 Ha (Kementerian Dalam Negeri Republik Indonesia Direktorat Jenderal Bina Pemerintahan Desa, 2020c). Salah satu hasil kebun yang dihasilkan Nagari Salibutan yaitu Buah Pepaya. Pepaya dengan Bahasa latin (Carica papaya L.) memiliki banyak manfaat, hampir seluruh bagian tanaman pepaya dapat dimanfaatkan, mulai dari daging buah, biji, hingga daunnya. Buah pepaya banyak mengandung nutrisi yang bermanfaat bagi Kesehatan, 
terutama serat dan vitamin A. Vitamin A baik untuk kesehatan mata, sementara seratnya sangat baik untuk kesehatan system pencernaan (Mandalika, et al., 2014).

Buah papaya yang di panen umumnya memiliki rata-rata harga jual Rp.2.000/kg (Faisal, 2015). Pada saat dipanen harga pepaya cenderung turun karena jumlahnya yang melimpah, sementara itu pemanfaatan buah Pepaya selain untuk dikonsumsi secara langsung belum ada. Agar buah pepaya memiliki nilai ekonomi yang tinggi, maka perlu inovasi untuk menghasilkan produk jual lainnya. Salah satu produk yang dihasilkan dari buah pepaya yaitu Sabun, buah Pepaya yang matang dan tidak laku di pasar juga bisa digunakan agar tidak menjadi sampah yang merusak lingkungan. Sabun yang dihasilkan buah pepaya juga sehat karena proses pembuatannya yang alami, sabun ini bisa dijadikan souvenir asli Kenagarian Salibutan. Disamping itu sabun dari buah papaya saat pandemi COVID-19 saat sekarang, bisa dimanfaatkan masyarakat untuk sering mencucitangan. Selain menjagajarak dan menghindari kerumunan, mencuci tangan merupakan salah satu protocol kesehatan yang dianjurkan pemerintah agar penyebaran COVID-19 dapat terkendali.

Berdasarkan latar belakang ini, tim pelaksana dari jurusan Biologi FMIPA UNP, sesuai dengan Dharma ketiga dari Tri Dharma Perguruan Tinggi bekerjasama melaksanakan kegiatan Pengabdian kepada Masyarakat di Kenagarian Salibutan yaitu dalam bentuk kegiatan PKM Pelatihan Homemade Pepaya Soap Bagi Kelompok Ibu Produktif di Kenagarian Salibutan Kecamatan Lubuk Alung Kabupaten Padang Pariaman.

\section{Metode}

Cara penerapan IPTEK dilakukan dalam bentuk workshop yang dibagi atas dua bentuk kegiatan yaitu:

1. Penyampai materi oleh narasumber tentang manfaat dan cara mengolah buah Pepaya menjadi sabun.

2. Workshop/Praktek mengenai penerapan proses safonifikasi dalam pengolahan buah Pepaya menjadi sabun.

Untuk melihat keberhasilan dari kegiatan ini, perlu dilakukan evaluasi. Supaya penyuluhan dan pelatihan ini berjalan dengan lancer sesuai dengan apa yang direncanakan, maka dilakukan beberapa kegiatan persiapan sebagai berikut:

1. Melaksanakan pertemuan/diskusi dengan anggota pelaksana pelatihan untuk merumuskan langkah-langkah dalam pelaksanaan pelatihan ini, terutama yang berhubungan dengan penyusunan proposal, penetapan jadwal, pembagian tugas dan menentukan materi pelatihan. Tujuan pertemuan dan diskusi ini adalah dalam rangka pemantapan rencana dan mencari masukan baru yang berhubungan dengan pelatihan yang dilaksanaan.

2. Memilih tempat pelaksanaan pengabdian yang sesuai dengan latar belakang kebutuhan masyarakat.

3. Pelaksanaan kegiatan berikutnya adalah menetapkan peserta, jadwal kegiatan dan tempat dimana kegiatan dilaksanakan.

4. Penetuan peserta, peserta ditentukan oleh Walinagari Salibutan Kecamatan Lubuk Alung Kabupaten Padang Pariaman.

Dalam pelaksanaan kegiatan pengabdian kepada masyarakat ini, tim pelaksana memiliki kepakaran yang sesuai dengan pengabdian masyarakat ini yaitu dibidang biologi dan teknik lingkungan khusus mata kuliah anatomi dan morfologi tumbuhan, bioteknologi, mikrobiologi, daur ulang sampah serta kewirausahaan. Ketua dan anggota pengusul adalah dosen yang mengajar dijurusan biologi FMIPA UNP dan Dosen Program Studi Teknik Lingkungan Fakultas Teknik UNU Sumbar. Dalam PKM ini tim dibantu oleh laboran dan mahasiswa yang sudah mengambil mata 
kuliah bioteknologi dan biokimia dimana mereka sudah mempraktekan pembuatan sabun dalam proses pembelajaran.

Berdasarkan pengalaman diatas dan permintaan dari masyarakat setempat, maka kami dari tim pengabdian Jurusan Biologi FMIPA UNP dan Program Studi Teknik Lingkungan Fakultas Teknik UNU Sumbar akan mengadakan PKM Pelatihan Homemade Papaya Soap Bagi Kelompok Ibu Produktif di Kenagarian Salibutan Kecamatan Lubuk Alung Kabupaten Padang Pariaman. Dalam pelatihan ini akan disosialisasikan dan diikuti dengan praktek teknik-teknik mengolah buah pepaya menjadi produk bernilai ekonomi tinggi yaitu sabun. Selain itu juga akan disosialisasikan dampak sampah organik terhadap lingkungan, sehingga masyarakat mau memanfaatkan sampah menjadi produk yang bisa dimanfaatkan lagi. Produk yang dihasilkan dari pemanfaatan buah-buah bisa dijadikan souvenir khas dari daerah setempat. Hasil yang diharapkan adalah masyarakat mampu mengolah buah papaya menjadi produk yang bernilai ekonomi.

\section{Hasil dan Pembahasan}

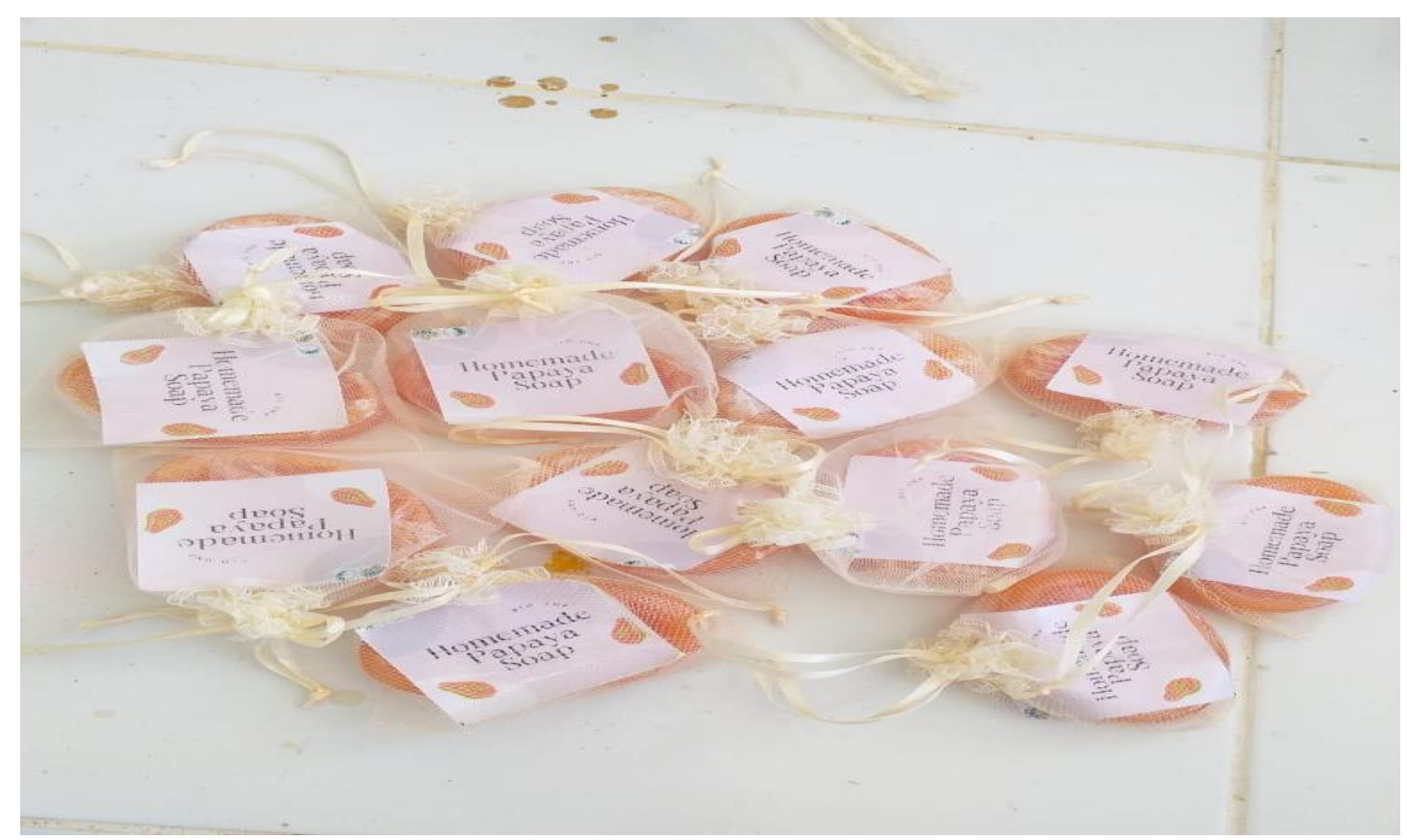

Gambar 1. Produk sabun dari buah Pepaya yang dapat dijadikan souvenir khas Nagari Salibutan Kecamatan Lubuk Alung Kabupaten Padang Pariaman.

Gambar 1 menunjukan produk sabun yang dihasilkan dari buah pepaya. Sabun yang dihasilkan dari buah pepaya adalah sabun yang sehat karena proses pembuatannya yang alami, sabun ini bisa dijadikan souvenir asli Kenagarian Salibutan, disamping itu didaerah ini juga terdapat beberapa objek wisata air seperti Air Terjun Nyarai sehingga souvenir sabun tersebut sangat menunjang dijual kepada pengunjung wisata Air Terjun Nyarai tersebut. Sabun dari buah papaya saat pandemi COVID-19 saat sekarang, juga bisa dimanfaatkan masyarakat untuk sering mencuci tangan. Selain menjaga jarak dan menghindari kerumunan, mencuci tangan merupakan salah satu protocol kesehatan yang dianjurkan pemerintah agar penyebaran COVID-19 dapat terkendali. 


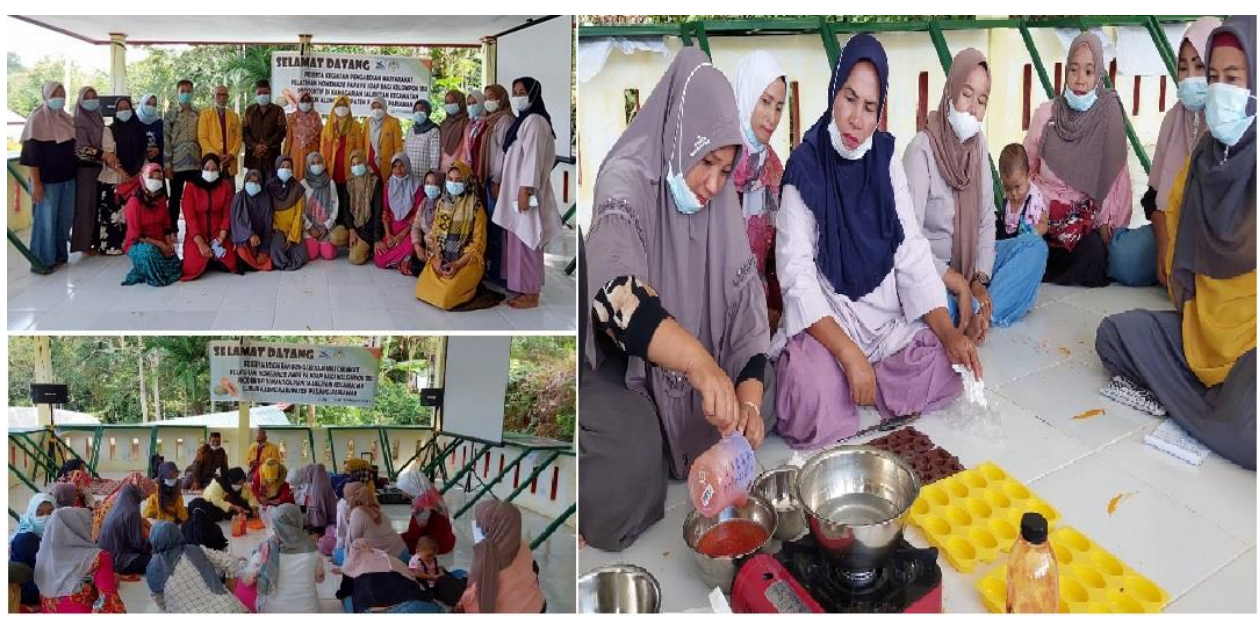

Gambar 2. Pelaksanaan pelatihan Homemade Papaya Soap bagi kelompok Ibu

Produktif di Kenagarian Salibutan Kecamatan Lubuk Alung Kabupaten Padang Pariaman.

Gambar 2 menunjukan pelaksanaan kegiatan pelatihan Homemade Pepaya Soap bagi Ibu Produktif di Kenagarian Salibutan Kecamtan Lubuk Alung Kabupaten Padang Pariaman. Kegaiatan pengabdian ini dilakukan dalam dua bentuk yaitu (1) Penyampai materi oleh nara sumber tentang manfaat dan cara mengolah buah Pepaya menjadi sabun, serta (2) Workshop/Praktek mengenai penerapan proses safonifikasi dalam pengolahan buah Pepaya menjadi sabun. Pelatihan/Praktek dilakukan pada hari Sabtu tanggal 24 Juli 2021. Para peserta yang hadir pada kegiatan tersebut sebanyak 20 orang yang terdiri dari kelompok Ibu PKK Nagari Salibutan Kecamatan Lubuk Alung Kabupaten Padang Pariaman.

\section{Kesimpulan}

Berdasarkan hasil kegiatan dan pembahasan, maka kesimpulan sebagai berikut : 1). Pelatihan pembuatan sabun dari buah pepaya telah berhasil dilaksanakan dengan penyerapan materi teori dan praktek oleh peserta dengan baik. Pemanfaatan buah pepaya untuk menjadi produk bernilai ekonomi sabun menjadi pengetahuan baru bagi peserta. Di samping itu peluang usaha pemberdayaan Ibuk Produktif di Kenagarian Salibutan untuk membuat sabun dari buah pepaya sebagai souvenir khas daerah tersebut bisa dilakukan. 2). Hasil menunjukan bahwa peserta mampu mempraktekan sendiri wawasan dan keterampilan yang didapat selama pelatihan, sehingga peserta dapat membuat sabun dari buah papaya secara mandiri.

\section{Daftar Pustaka}

Faisal, H. N. (2015). Analisis Pendapatan Usahatani Dan Saluran Pemasaran Pepaya (Carica Papaya L) Di Kabupaten Tulungagung (Studi kasus di Desa Bangoan, Kecamatan Kedungwaru, Kabupaten Tulungagung). Jurnal Agribis, 11(13), 12-28.

Kementerian Dalam Negeri Republik Indonesia Direktorat Jenderal Bina Pemerintahan Desa. (2020a). Data Pokok Desa/Kelurahan.

http://prodeskel.binapemdes.kemendagri.go.id/dpokok grid t01/

Kementerian Dalam Negeri Republik Indonesia Direktorat Jenderal Bina Pemerintahan Desa. (2020b). Daftar Isian Tingkat Perkembangan Desa Dan Kelurahan.

http://prodeskel.binapemdes.kemendagri.go.id/laporan terkini tingkat/laporan terkini tingk at.php? 
Kementerian Dalam Negeri Republik Indonesia Direktorat Jenderal Bina Pemerintahan Desa. (2020c). Daftar Isian Potensi Desa Dan Kelurahan.

http://prodeskel.binapemdes.kemendagri.go.id/laporan terkini potensi/laporan terkini pote nsi.php?

Mandalika, W. C., Wicaksono, D. A., \& Leman, M. A. (2014). Pengaruh Konsumsi Pepaya (Carica Papaya) dalam Menurunkan Indeks Debris pada Anak Usia 10-12 tahun di SDN 103 Manado. e-GiGi, 2(2). 